\title{
Editorial \\ Polymer Membranes for Gas Separation
}

\author{
Elsa Lasseuguette ${ }^{1, *(D)}$ and Bibiana Comesaña-Gándara $2, *$ D \\ 1 School of Engineering, University of Edinburgh, Robert Stevenson Road, Edinburgh EH9 3FB, UK \\ 2 Institute of Sustainable Processes (ISP), University of Valladolid, 47011 Valladolid, Spain \\ * Correspondence: E.Lasseuguette@ed.ac.uk (E.L.); bibiana.comesana@uva.es (B.C.-G.)
}

Citation: Lasseuguette, E.;

Comesaña-Gándara, B. Polymer

Membranes for Gas Separation.

Membranes 2022, 12, 207.

https://doi.org/10.3390/

membranes12020207

Received: 21 January 2022

Accepted: 5 February 2022

Published: 10 February 2022

Publisher's Note: MDPI stays neutral with regard to jurisdictional claims in published maps and institutional affiliations.

Copyright: (c) 2022 by the authors. Licensee MDPI, Basel, Switzerland. This article is an open access article distributed under the terms and conditions of the Creative Commons Attribution (CC BY) license (https:// creativecommons.org/licenses/by/ $4.0 /)$.
Over the past decade, polymeric membranes have been widely investigated for a variety of industrial gas separation applications. In today's competitive and ever-changing environment, membrane gas separation is now widely accepted as an economic process to produce moderate purity stream gases.

This Special Issue on "Polymer Membranes for Gas Separation" of the journal Membranes aims to assess the state-of-the-art and future developments in the field of polymeric membranes. Various topics have been discussed, including the synthesis and characterization of novel membrane materials, membrane aging, and the impact of process conditions on transport phenomena, with the desire to improve the gas separation process in all the articles. There are nine contributions, namely, eight articles and one review, in this Special Issue.

Zang et al. [1] synthetized new polymers based on phenylacetylene monomers having one or two carbamate moieties in order to enhance the $\mathrm{O}_{2} / \mathrm{N}_{2}$ separation performance. The presence of two carbamate groups induced a better membrane-forming ability and a higher oxygen solubility and diffusivity thanks to the cistransoid conformation, which is flexible. Thus, these materials presented a greater oxygen permeability compared to the one without carbamate group, 420 Barrer and 3 Barrer, respectively.

In the same way, Rodriguez-Gonzalez et al. [2] synthetized a new set of polyimides in order to study the impact of different chemical moieties (acyclic alkyl- $N$-carbamoyl group with different alkyl chains) on gas properties. For all gases, the authors noticed a decrease in the alkyl chains as they were shortened. These results were correlated with the calculated FFV and the obtained d-spacing values.

Liu et al. [3] described how graphdiyne could make an excellent candidate for hydrogen purification. In their paper, they investigated the gas permeation of four pure gases $\left(\mathrm{H}_{2}\right.$, $\mathrm{N}_{2}, \mathrm{CO}_{2}$, and $\mathrm{CH}_{4}$ ) and binary mixtures through a theoretical study based on MD and DFT calculations. Thanks to its uniform pore size $(2.1 \AA)$ and atomic thickness, the graphdiyne presented approximatively infinite selectivities of $\mathrm{H}_{2}$ over $\mathrm{N}_{2}, \mathrm{CO}_{2}$, and $\mathrm{CH}_{4}$. Moreover, with a slight presence of surface charges, the authors showed that the $\mathrm{H}_{2}$ permeance of the binary $\mathrm{H}_{2} / \mathrm{CO}_{2}$ could be increased up to $2 \times 8 \times 10^{5} \mathrm{GPU}$, which is several orders of magnitude greater than the existing experiments.

Begni et al. [4] developed new materials to enhance gas separation over time. They synthesized new hypercrosslinked polymers based on the Friedel-Crafts reaction between a tetraphenyl methane monomer and a bromomethyl benzene monomer in order to use them as fillers in PIM-1 mixed matrix membranes. According the reaction process, two fillers have been obtained, with different particle sizes and surface areas, $498 \mathrm{~nm}$ and $823 \mathrm{~m}^{2} / \mathrm{g}$ and $120 \mathrm{~nm}$ and $990 \mathrm{~m}^{2} / \mathrm{g}$, respectively. The authors showed that the presence of the fillers induced a slowdown of the membrane's physical aging, which is greater for the smaller filler. After almost three years of aging, mixed matrix membranes retained approximatively $40 \%$ of the initial $\mathrm{CO}_{2}$ permeability while pure PIM- 1 showed a reduction of $85 \% .{ }^{13} \mathrm{C}$ spin-lattice relaxation time studies showed that this slow-down in aging is due to the interactions between the PIM-1 chain and the HCP fillers. 
The enhancement of gas separation performance could also be achieved by investigating the effect of the process conditions, such as process temperature or the presence of water or other pollutants in the feed. Casado-Coterillo et al. [5] studied the effect of the presence of water and organic pollutants in $\mathrm{CO}_{2} / \mathrm{CH}_{4}$ separation within a hydrophilic and hydrophobic composite membrane. The authors showed that the permeance of the hydrophobic membrane was affected by the presence of damp impurities with an increase in $\mathrm{CO}_{2}$ permeance, while the permeance and selectivity of the hydrophilic membrane were almost invariable in the presence of humid streams. By addition of toluene, used as model organic pollutants, the differences were enhanced. Moreover, the $\mathrm{CO}_{2}$ permeances decreased with increasing $\mathrm{CO}_{2}$ concentration in the feed in a more remarkable way for the hydrophobic PDMS composite membrane than for the hydrophilic IL-CS-based composite membrane, which may be attributed to the water-facilitated transport through the hydrophilic membrane. By consequence, the tuning up of the hydrophilic/hydrophobic character of the membrane surface can be an effective way of improving facilitated transport properties and improving membrane performance in $\mathrm{CO}_{2}$ capture applications.

Nemestothy et al. [6] also studied the impact of the presence of pollutants on $\mathrm{CO}_{2} / \mathrm{CH}_{4}$ separation for a polyimide membrane. Commercial hollow fibers based on polyimide have been tested in the presence of naturally occurring contaminants of natural gases, namely, hydrogen sulfide, dodecane, and the mixture of aromatic hydrocarbons (benzene, toluene, xylene). The authors showed that all of the investigated pollutants had an impact on the membrane's performance but in different ways and to different extents. Hydrogen sulfide increased the permeability of both $\mathrm{CO}_{2}$ and $\mathrm{CH}_{4}$, and the $\mathrm{CO}_{2} / \mathrm{CH}_{4}$ selectivity had a decreasing tendency as a function of increasing $\mathrm{H}_{2} \mathrm{~S}$ exposures. In the case of dodecane, the permeability of $\mathrm{CO}_{2}$ and $\mathrm{CH}_{4}$ decreased moderately by increasing the degree of exposure, while the $\mathrm{CO}_{2} / \mathrm{CH}_{4}$ selectivity, according to tendencies, was left unaffected. By contrast, the larger exposures of aromatic hydrocarbons caused the increase in gas permeabilities; however, the corresponding trends indicated only marginal changes in the $\mathrm{CO}_{2} / \mathrm{CH}_{4}$ selectivity.

Belaissaoui et al. [7] showed as well that by playing on the selective layer thickness and the carrier concentration of a facilitated transport membrane, it is possible to enhance the separation performance. Their analyses are based on experimental measurements of $\mathrm{CO}_{2}$ and $\mathrm{N}_{2}$ fluxes through a hybrid fixed-site carrier membrane, based on poly(allyl amine) matrix and on analytical solutions of the facilitation factor mathematically described by means of differential equations expressing a steady-state nonlinear diffusion reaction problem. The dedicated parametric analysis demonstrated that decreasing the selective layer thickness to $0.1 \mu \mathrm{m}$ together with doubling of the total carrier concentration would theoretically shift the membrane performance far above the Robeson upper bound for the $\mathrm{CO}_{2} / \mathrm{N}_{2}$ pair. However, this potential path for membrane performance improvement has to be weighted by the possible depletion in the reaction complex effective diffusivity.

Benedetti et al. [8] prepared new mixed matrix membranes based on poly $(2,6$-dimethyl1,4-phenylene oxide) (PPO) and particles of the size-selective Zeolitic Imidazolate Framework 8 (ZIF-8). The aim was to increase the permselectivity properties of pure PPO. The authors showed that the addition of $45 \%$ wt ZIF8 improved the separation performance of PPO by an increase of $800 \%$ for $\mathrm{CO}_{2}$ and He permeability coefficients. The temperature increase also yielded a simultaneous increase of permeability and selectivity, indicating that such membranes can have potential for applications at high temperatures.

Finally, Vermaak et al. [9] described in their review an overview of membrane-based electrochemical hydrogen separation technologies. Electrochemical membranes are seen as a promising alternative to pressure-driven membranes. Electrochemical membranes are known to generate electricity (fuel cells) or to apply it (water electrolysis), and they are also used to purify/enrich and compress hydrogen streams. They detailed the working principle of electrochemical hydrogen separation and discussed the impact of condition processes, such as temperature, gas mixture, and catalysts, on the separation performance. 
In conclusion, the findings and critical discussions from these contributions highlight the importance of membrane materials and the processes for gas separation.

Funding: This research received no external funding.

Acknowledgments: The editors would like to thank the authors for their high-quality outputs and Lydia Li for her patient and motivating help and assistance.

Conflicts of Interest: The authors declare no conflict of interest.

\section{References}

1. Zang, Y.; Lun, Y.; Teraguchi, M.; Kaneko, T.; Jia, H.; Miao, F.; Zhang, X.; Aoki, T. Synthesis of Cis-Cisoid or Cis-Transoid Poly(Phenyl-Acetylene)s Having One or Two Carbamate Groups as Oxygen Permeation Membrane Materials. Membranes 2020, 10, 199. [CrossRef] [PubMed]

2. Rodríguez-González, F.E.; Pérez, G.; Niebla, V.; Jessop, I.; Martin-Trasanco, R.; Coll, D.; Ortiz, P.; Aguilar-Vega, M.; Tagle, L.H.; Terraza, C.A.; et al. New Poly(imide)s Bearing Alkyl Side-Chains: A Study on the Impact of Size and Shape of Lateral Groups on Thermal, Mechanical, and Gas Transport Properties. Membranes 2020, 10, 141. [CrossRef] [PubMed]

3. Liu, Q.; Cheng, L.; Liu, G. Enhanced Selective Hydrogen Permeation through Graphdiyne Membrane: A Theoretical Study. Membranes 2020, 10, 286. [CrossRef] [PubMed]

4. Begni, F.; Lasseuguette, E.; Paul, G.; Bisio, C.; Marchese, L.; Gatti, G.; Ferrari, M.-C. Hyper Cross-Linked Polymers as Additives for Preventing Aging of PIM-1 Membranes. Membranes 2021, 11, 463. [CrossRef] [PubMed]

5. Casado-Coterillo, C.; Garea, A.; Irabien, Á. Effect of Water and Organic Pollutant in $\mathrm{CO}_{2} / \mathrm{CH}_{4}$ Separation Using Hydrophilic and Hydrophobic Composite Membranes. Membranes 2020, 10, 405. [CrossRef] [PubMed]

6. Nemestóthy, N.; Bakonyi, P.; Lajtai-Szabó, P.; Bélafi-Bakó, K. The Impact of Various Natural Gas Contaminant Exposures on $\mathrm{CO}_{2} / \mathrm{CH}_{4}$ Separation by a Polyimide Membrane. Membranes 2020, 10, 324. [CrossRef] [PubMed]

7. Belaissaoui, B.; Lasseuguette, E.; Janakiram, S.; Deng, L.; Ferrari, M.-C. Analysis of $\mathrm{CO}_{2}$ Facilitation Transport Effect through a Hybrid Poly(Allyl Amine) Membrane: Pathways for Further Improvement. Membranes 2020, 10, 367. [CrossRef] [PubMed]

8. Benedetti, F.M.; De Angelis, M.G.; Degli Esposti, M.; Fabbri, P.; Masili, A.; Orsini, A.; Pettinau, A. Enhancing the Separation Performance of Glassy PPO with the Addition of a Molecular Sieve (ZIF-8): Gas Transport at Various Temperatures. Membranes 2020, 10, 56. [CrossRef] [PubMed]

9. Vermaak, L.; Neomagus, H.W.J.P.; Bessarabov, D.G. Recent Advances in Membrane-Based Electrochemical Hydrogen Separation: A Review. Membranes 2021, 11, 127. [CrossRef] [PubMed] 